\title{
Optimal filter design for power converters regulated by FCS-MPC in the MEA
}

Gao, Yuan; Yang, Tao; Dragicevic, Tomislav; Bozhko, Serhiy; Wheeler, Patrick; Zheng, Changming

Published in:

IEEE Transactions on Power Electronics

Link to article, DOI:

10.1109/TPEL.2020.3017862

Publication date:

2020

Document Version

Peer reviewed version

Link back to DTU Orbit

Citation (APA):

Gao, Y., Yang, T., Dragicevic, T., Bozhko, S., Wheeler, P., \& Zheng, C. (2020). Optimal filter design for power converters regulated by FCS-MPC in the MEA. IEEE Transactions on Power Electronics, 36(3), 3258 - 3268. https://doi.org/10.1109/TPEL.2020.3017862

\section{General rights}

Copyright and moral rights for the publications made accessible in the public portal are retained by the authors and/or other copyright owners and it is a condition of accessing publications that users recognise and abide by the legal requirements associated with these rights.

- Users may download and print one copy of any publication from the public portal for the purpose of private study or research.

- You may not further distribute the material or use it for any profit-making activity or commercial gain

- You may freely distribute the URL identifying the publication in the public portal 


\title{
Optimal Filter Design for Power Converters Regulated by FCS-MPC in the MEA
}

\author{
Yuan Gao, Student Member, IEEE, Tao Yang, Senior Member, IEEE, Tomislav Dragičević, Senior Member, IEEE, \\ Serhiy Bozhko, Senior Member, IEEE, Patrick Wheeler, Senior Member, IEEE and Changming Zheng, Student \\ Member, IEEE
}

\begin{abstract}
For the DC electrical power distribution system onboard more electric aircraft, the voltage quality of DC bus is of a great concern since there could be significant harmonics distortions when feeding different power electronics loads. This problem can be potentially addressed by introducing a DC filter to the point-of-load converters regulated by the finite control set model predictive control (FCS-MPC). To optimize this filter, Genetic Algorithm (GA) is utilized for searching the optimal design which guarantees a low mass and low power losses. Different from the conventional filter design methods, the proposed method treats $L C$ as design variables which need to be optimised while ensuring the output power quality. First, relations among variables, operation conditions and constraints are built based on commercial data and circuit simulations. Then, the design and optimization are developed with these relations and a Pareto-front is finally given by GA. After that, the best design is obtained by an index integrating two objectives. Lastly, the design approach is verified by experiment where an FCSMPC regulated converter was used as a particular example fed by three different $L C$ filters.
\end{abstract}

Index Terms-Filter design, genetic algorithm (GA), finite control set model predictive control (FCS-MPC), more electric aircraft (MEA).

\section{NOMENCLATURE}

$\begin{array}{ll}v_{s}, v_{d c} & \text { Pure source voltage, DC supply voltage. } \\ v_{C} & \text { DC capacitor voltage. } \\ Z_{\text {in }}, Z_{\text {out }} & \text { Input, output impedance. } \\ L_{0}, R_{0} & \text { DC microgrid impedance. } \\ L_{1} & L C \text { filter inductance. } \\ C_{1} & L C \text { filter capacitance. } \\ R_{1}, R_{2} & \text { Resistance of inductor and capacitor } \\ M, M_{\max } & \text { Total mass of } L C \text { filter. } \\ P L, P L_{\max } \text { Total power loss of } L C \text { filter. } \\ H, H_{\max } \quad \text { Magnetic field strength inductor core. }\end{array}$

Manuscript received August 26, 2019; re-submitted June 17, 2020; accepted August 4, 2020. This work was supported by the Clean Sky 2 Joint Undertaking under the European Union's Horizon 2020 research and innovation programme under grant agreement No 807081. (Corresponding Author: Tao Yang).

Y. Gao, T. Yang, S. Bozhko and P. Wheeler are with the Department of Electrical and Electronic Engineering, University of Nottingham, Nottingham, UK (e-mail: yuan.gao@nottingham.ac.uk; tao.yang@nottingham.ac.uk; serhiy.bozhko@nottingham.ac.uk; pat.wheeler@nottingham.ac.uk).

T. Dragicevic is with the Department of Energy Technology, Technical University of Denmark, Lyngby, Denmark (email: tomdr@elektro.dtu.dk).

C. Zheng is with the College of Control Science and Engineering, China University of Petroleum (East China), Qingdao, 266580, China (e-mail: jsxzzcm@126.com).

\begin{abstract}
$A_{c}, A_{c, \min }$ Cross-sectional area of toroidal core.
$l_{e} \quad$ Magnetic enclosed path in inductor.

$I_{L}, I_{p k} \quad$ RMS and peak value of inductor current.

$J, J_{\max } \quad$ Current density in inductor coil.

$d_{w} \quad$ Wire diameter of inductor winding.

$h_{\text {ins }} \quad$ Insulation thickness of inductor wire.

$N_{t}, N_{t, \max }$ Number of turns of inductor.

$C_{\text {win }} \quad$ Circumference of inner cycle of inductor core.

$B_{\max } \quad$ Max flux density in inductor core.

$\mu \quad$ Magnetic permeability.

$\gamma, \gamma_{\max } \quad$ Magnetic permeability drop.

$A_{L} \quad$ Nominal inductance factor of inductor core.

$P L_{L}, P L_{C}$ Inductor power loss and capacitor power loss.

$T_{\text {rise }}, T_{\text {lim }}$ Inductor temperature rise and its limitation.

$A_{c, s} \quad$ Inductor core surface area.

ESR Equivalent series resistance of capacitor.

$\tan \delta \quad$ Dissipation factor of capacitor series.

$R_{t h} \quad$ Thermal resistance of capacitor.

$I_{C}, I_{\max }^{R M S}$ RMS current of capacitor and its limit value.

$T_{a m b} \quad$ Ambient temperature.

$v_{i} \quad$ Possible voltage vectors across ac loads $(i=$ $1,2 \cdots 7)$.

$v_{n N} \quad$ Common mode voltage drop.

$v_{y N} \quad$ Voltages across the 3-phase loads $(y=a, b, c)$.

$S_{a}, S_{b}, S_{c} \quad$ Switch signals for 3 phases.

$x_{a}, x_{b}, x_{c} \quad$ Three-phase voltage variables.

$L_{f}, R_{f} \quad$ AC inductor inductance and resistance.

$C_{f} \quad$ AC filter capacitance.

$i_{f}, i_{o} \quad$ AC filter current and load current.

$i_{c} \quad$ DC current following into converter.

$v_{f}, v_{f}^{*} \quad$ AC filter voltage and its reference.

$T_{s} \quad$ Sampling period in FCS-MPC.

$\lambda_{d c} \quad$ Weighting factor of DC voltage control term.

$g_{a c}, g_{C} \quad \mathrm{AC}$ and DC-capacitor voltage control terms in

$g_{t}, G_{l i m} \quad \begin{aligned} & \text { cost function of FCS-MPC. } \\ & \text { Total cost function and its current limit term. }\end{aligned}$

$r \quad$ Integrated index of two optimization objectives.
\end{abstract}

\section{INTRODUCTION}

$\mathbf{M}$ OST of electric power today applies the alternatingcurrent (AC) form for generation and distribution. However, a common characteristic of power converters is that electricity appears in a direct-current (DC) form within its 
power conversion [1]. In DC forms, the number of power electronic devices can be significantly reduced also they are much simpler to control than ac without synchronization issues, reactive power flows and phase unbalances [2]. For the future more electric aircraft (MEA), replacing ac distribution with DC is a tendency which introduces many opportunities to optimize the aircraft electrical power system (EPS) since DC microgrid (MG) can potentially reduce the total weight of EPS, increase power efficiency, remove reactive power compensation devices thus save the aircraft manufacture, operation cost [3]-[5].

MEA concept has been widely accepted for decades and the EPS with DC distribution in MEA attracts much attention in this targeting field [3]-[8]. The conventional power distribution in aircraft utilizes a single-generator-per-bus paradigm integrated with switching components [3], [5]. In [3], a 'singlebus' concept was proposed for the on-board MG where all sources and loads are connected to a single DC distribution bus (shown in Fig. 1). However, this bus is prone to instability when fed by multiple generators and connected to various onboard loads. Besides, when fed from a fast switching rectifier, the long cable with large impedance can lead to bus voltage drops and oscillations. The paper [3] clearly addressed the droop control problem on generator side to regulate the DC bus but did not study the regulation issues of onboard loads in detail. This paper adds a filter for converter-based loads to actively regulate the DC-link voltage and explores an optimal design method for this filter following the constraints in MILSTD-704F [9].

Therefore, the motivation of adding a filter feeding converters is from the potential destabilization on DC bus. In MEA, the main engine generator is directly coupled to the jet engine via a gearbox and thus the frequency of generator output power is proportional to engine speed [10]. In a generalized DC EPS, the power supply could have many frequency components in different flight phases (for example take-off, cruise, descent, landing and taxiing) due to the variation in engine speed. The DC bus may have a large ripple due to the control of the bus voltage. This underlies the interest of adding a filter to the potential aircraft converter-based loads. Furthermore, an input filter is also required by the inverter system to smooth the DC bus ripple and to meet the EMI requirement [11].

Filter design commonly incorporates sizing models of inductor and capacitor where physical parameters, inner resistance and thermal function should be considered. In [12], an optimization approach of passive components is presented for rectifiers but it only considers one-boost-inductor topology using commercial cores. $L C L$ harmonic filters are designed in [13] based on a generic optimization method for rectifiers where filter capacitance is derived as a function of the gridside inductance to fulfil grid standard. A comprehensive noniterative analytical $L C L$ filter design method is presented in [14] where the converter current ripple is analysed to determine the limit of boost inductance. Different from these papers, the core loss [15] of inductor is not considered here since the inductor is applied in DC form thus core loss is negligible; toroidal powder cores are selected for inductor design thus there is no air gap in them. However, capacitor

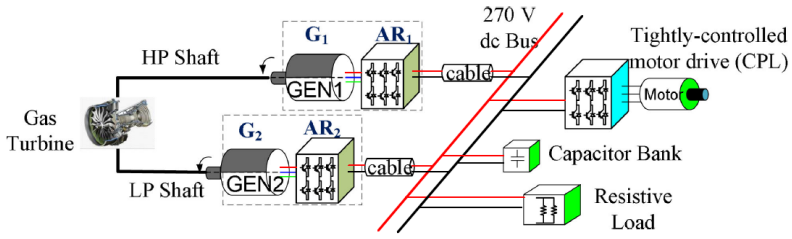

Fig. 1. One possible EPS in the MEA [3].

is designed using a similar way in which dissipation factor enables the capacitor loss estimation.

It is noted that $L C$ limits are usually calculated based on the simplified circuit and harmonic analysis [12], [14], [16]. And actual $L C$ values are given to the optimization based on commercial components [12], [13] or the predefined ripple/THD limits [13], [17], [18]. In contrast, the work in this study treats $L C$ values as design variables in the optimization process which enables global optimization. Ripple/THD limits are carefully considered in the optimization constraints. Circuit simulation is embedded into the optimization to avoid errors from analysis simplifications. As shown in Section III, the geometry parameters and physical constraints based on the commercial data are also derived in the sizing process. Another novelty is the consideration of filter internal resistance and its damping effect in the automatic integrated design process.

Apart from the filter design, the other main part of this work is the regulation of point-of-load converters which supply power to electronic loads. Point-of-load converter control has been challenging since such electronic loads have a negative incremental impedance. Among the control strategies for such loads, the finite control set model predictive control (FCSMPC) [19]-[21] is applied since it allows a much better transient response and similar steady-state performance compared to linear control methods [19]. Furthermore, FCS-MPC is characterized by its robust capability to deal with over $100 \%$ control parameter mismatch which is a big gain over linear control methods [22]. Thus, FCS-MPC has started to be widely used to various power electronic converters [23]. However, variable switching frequency is a specific drawback of FCS-MPC, which significantly complicates the filter design process compared to standard design procedures for filters of converters operated with linear control systems. This drawback is the main motivation for the study performed in this paper.

In this paper, a cost function with two voltage stabilization terms is adopted. Different from the state-of-the-art FCS-MPC methods, trade-off study among these two terms is studied by using a weighting factor (WF) as one variable in the optimization. Based on a circuit simulation, the design space is searched to select a good WF (subject to constraints); thus the optimal filter design can be obtained with excellent control performance. Moreover, existing literatures in FCSMPC focused on their proposed control models using fixed and predetermined filter components [19]-[25], this work utilizes Pareto-front Genetic Algorithm (GA) [26], circuit simulation, component sizing to search the optimal filter design for converter-based loads. Noting that the proposed design method is independent with the control strategy thus applicable for 


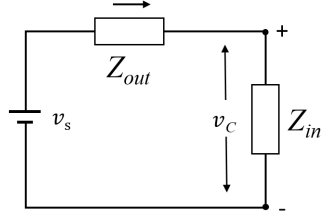

(a) Equivalent Thevenin circuit.

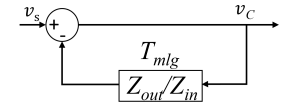

(b) Equivalent block diagram.
Fig. 2. Equivalent Thevenin circuit and a block diagram of a DC MG [19].

any other strategies, e.g. linear control. Similarly, typical parameters in other strategies can be applied within the proposed optimization methodology to ensure good control performance of the optimal design.

This study utilizes a common scenario in practical application, an $L C$ filter, but the proposed design and optimization method can be used in any other types of filters. Mass and power loss of the filter are set as objectives of the GA optimization. Based on GA modelling, filter sizing, circuit system controlled by FCS-MPC, this paper proposes a databased methodology for the aforementioned problems whose applications are not restricted to aircraft systems.

\section{SYSTEM DESCRIPTION}

Fig. 1 shows a DC electrical power distribution system (EPDS) in the MEA where two generators take power from one aircraft engine and supply power to the main DC bus through power electronic converters. Electrical drive loads (can be electromechanical actuators) are connected to the main DC bus through point-of-load converters for power conditioning and voltage regulation. These drives can extract steady power from MG under varying voltage thus, are often referred as constant power loads (CPLs) whose incremental input impedance is negative [27]. Thus, it tends to destabilize the system to which it is connected. This study applies a DC $L C$ filter in front of the converter to stabilize the DC-link voltage. It is worthy of investigating the impedance effect to understand the necessary conditions for DC-link voltage regulation.

The equivalent Thevenin circuit of the system is constructed in Fig. 2 showing a CPL in EPDS. The overall power supply part can then be represented by a voltage source $v_{s}$ and an output impedance $Z_{\text {out }}$, whereas effects of the load part can be aggregated within an input impedance $Z_{i n}$. The dynamics of such a system can be described by the ratio $Z_{\text {out }} / Z_{\text {in }}$. The following relation is valid for dynamic analysis of stability criteria:

$$
v_{C}=v_{s} \cdot \frac{Z_{\text {in }}}{Z_{\text {in }}+Z_{\text {out }}}=v_{s} \cdot \frac{1}{1+Z_{\text {out }} / Z_{\text {in }}} .
$$

The stability problem of the CPL is commonly solved by the Nyquist stability criterion, i.e. properly shaping impedances in (1) to ensure the ratio $Z_{\text {out }} / Z_{\text {in }}$ satisfies the Nyquist criterion [19]. There are three general ways of achieving the mandatory stability margins of the system: a. Active damping of $Z_{\text {out }} ; \mathrm{b}$. Passive damping of $Z_{\text {out }}$; c. Active damping of $Z_{i n}$.

One possibility to shape $Z_{\text {out }}$ is by actively controlling the active-front end interface on the DC bus. Some feasible

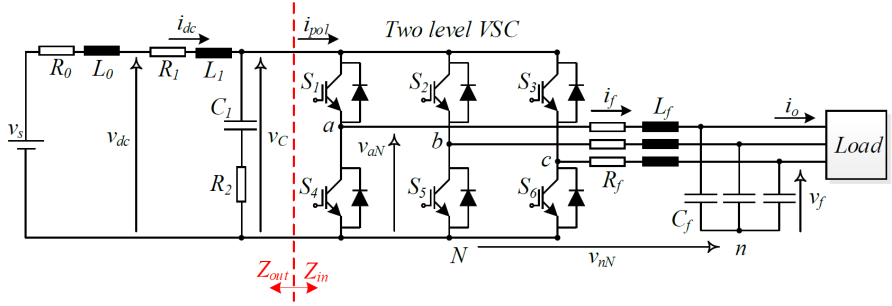

Fig. 3. A CPL case study: Two-level VSC fed from a DC grid via $L C$ filter and supplying an ac load.

approaches are the proportional control of active front-end [28], power-conditioning module [29] and droop control [3], [8], [30]. However, the active-front end interface is not available in many industrial applications of DC MGs where only unidirectional power flow is required [19]. Another approach of achieving stability is passive damping of $Z_{\text {out }}$ which is based on increasing the capacitance or connecting additional resistors in series. Obviously, it usually requires a capacitor with big volume/weight which is not ideal for aircraft application. In order to improve the power density and prolong the lifetime of the converter system, a large capacitance DC-bus capacitor is intended to be replaced by an $L C$ filter consisting of an inductor and a small capacitance film capacitor [11]. Therefore, this paper utilized the other way to actively shape $Z_{\text {in }}$ by FCS-MPC for a passive front-end rectifier with an input $L C$ filter. The studied configuration is shown in Fig. 3 , where a two-level voltage source converter (VSC) feeding a stand-alone ac load is supplied from the passive front-end interface. Thus, $L_{0}$ with $R_{0}$ and an $L C$ filter represent $Z_{\text {out }}$, while VSC and ac loads are aggregated within $Z_{\text {in. }} . Z_{\text {out }}$ can be calculated as follows:

$$
Z_{\text {out }}=\frac{\left(1+s C_{1} R_{2}\right) \cdot\left[R_{0}+R_{1}+s\left(L_{0}+L_{1}\right)\right]}{s^{2}\left(L_{0}+L_{1}\right) C_{1}+s C_{1}\left(R_{0}+R_{1}+R_{2}\right)+1},
$$

where $L_{0}$ and $R_{0}$ denote the equivalent DC grid impedance, $L_{1}$ is the filter inductance, $R_{1}$ is the resistance of filter inductor coil, $C_{1}$ is the filter capacitance, $R_{2}$ is the resistance of the capacitor. The following section will discuss the sizing models for the filter components which serve as the basis of the proposed filter design and optimization methodology.

\section{Modelling of Filter Components}

The $L C$ values for the filter are conventionally calculated based on current ripple/THD limits or required harmonic attenuation under precisely specified switching frequency [13], [14], [17], [18]. However, these equations can only give extreme $L C$ values which do not guarantee the minimum mass $(M)$ and power loss $(P L)$ of the whole filter system. Moreover, they are not applicable here due to the variable switching frequency of FCS-MPC. To solve this, commercial data based filter optimization [12], [13] can be used. This paper proposes an automated and integrated optimal filter design method with embedded circuit simulations where all required ripple/THD are carefully considered as the optimization constraints. This section will present the sizing models for $L$ and $C$ to serve the optimization. These models not only deduce the resistance 


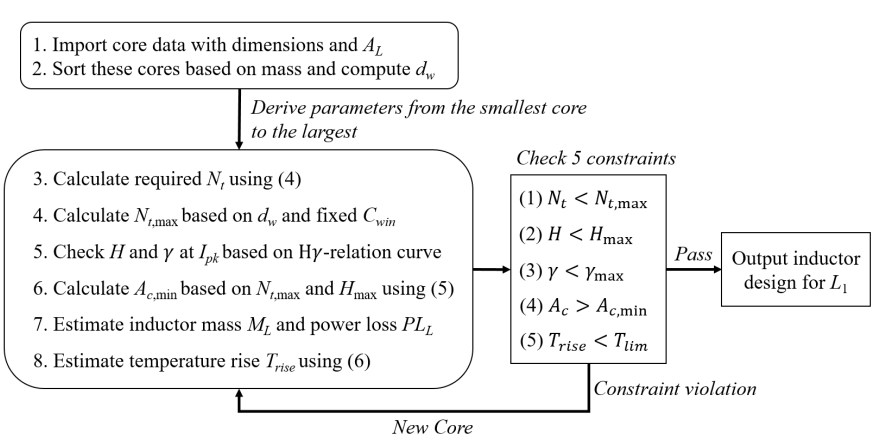

Fig. 4. Inductor sizing model.

$R_{1}$ and $R_{2}$, but consider various constraints in the filter sizing process.

\section{A. Inductor Sizing Function}

Regarding the inductor in this filter, toroidal powder cores made by magnetic material MPP60 [31] from inductor core manufacturer Magnetics Inc. are employed since they have good AC and DC magnetization properties and provide achievable inductance. There are five constraints in this sizing model: maximum number of turns $N_{t, \max }$, field intensity $H_{\max }$, permeability drop $\gamma_{\max }$, minimum cross-section area $A_{c, \min }$ and maximum temperature rise $T_{l i m}$. Cores that only meet all these requires can be reserved in the selection pool. At the end, the smallest core is chosen from the remaining available cores, its mass and loss with required $N_{t}$ can be output. If there is no core left in the selection pool, the inductor sizing fails.

As shown in Fig. 4, in the inductor sizing procedure, discrete core sizes and commercial data are first imported to form a selection pool and the inductors are custom designed based on the maximum energy storage requirement. The RMS current $I_{L}$ (and its peak value $I_{p k}$ ) flowing into the inductor should be given to to define the required wire diameter as:

$$
d_{w}=2 \sqrt{\frac{I_{L}}{\pi J_{\max }}}+2 h_{\text {ins }}
$$

where $J_{\max }$ is the maximum current density and $h_{\text {ins }}$ is the coil insulation thickness. For the designed/selected inductance $L_{1}$, the required number of turns $N_{t}$ can be given as:

$$
N_{t}=\sqrt{\frac{L_{1}}{A_{L}}}
$$

where the core's nominal inductance factor $A_{L}$ accounts for material saturation limitation [31]. With the derived $N_{t}$, the field intensity $H$ can be obtained from $N_{t} I_{p k} / l_{e}$ ( $l_{e}$ is core magnetic path length). The maximum number of turns $N_{t, \max }$ can be physically computed using $d_{w}$ and the minimum wire space which is limited at the inner circumference of each core, $C_{w i n}$. In addition, the core cross-section area limit $A_{c, \min }$ can be given as:

$$
A_{c, \min }=\frac{\Theta}{B_{\max }}=\frac{I_{L} L_{1}}{\gamma \mu H_{\max } N_{t, \max }},
$$

where $H_{\max }$ is a predefined field intensity, $\mu$ is magnetic permeability, $\gamma$ is permeability drop which is determined by

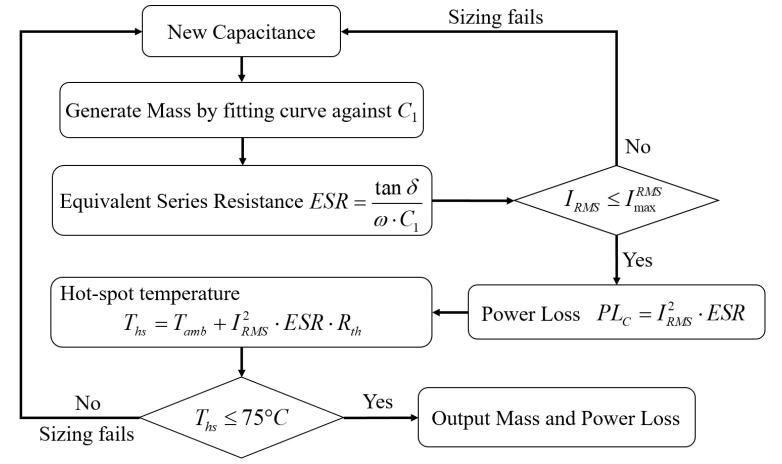

Fig. 5. Capacitor sizing model.

the manufacturer given non-linear $H \gamma$-relation curve. $R_{1}$ is obtained by $N_{t}, d_{w}$, copper conductivity and turn length. Coil mass can be simply given by copper density, $N_{t}$, turn length and $d_{w}$. Finally, the core temperature rise is estimated using (6) from [31] $\left(T_{\text {lim }}\right.$ is set as $\left.55^{\circ} \mathrm{C}\right)$ :

$$
T_{\text {rise }}=\left(\frac{P L_{L}}{A_{c, s}}\right)^{0.833}
$$

where $P L_{L}$ is the inductor loss (equals $I_{L}^{2} R_{1}$ ), $A_{c, s}$ is the core surface area.

\section{B. Capacitor Sizing Function}

The capacitor of $L C$ filter is selected from the EPCOS B2562* MKP DC film capacitors series [32]. The dissipation factor is specified as:

$$
\tan \delta=\left\{\begin{array}{l}
1.2 \times 10^{-3}, C_{1}<450 \mu \mathrm{F} \\
1.5 \times 10^{-3}, 450 \mu \mathrm{F} \leq C_{1} \leq 800 \mu \mathrm{F} \\
2.0 \times 10^{-3}, C_{1}>800 \mu \mathrm{F}
\end{array}\right.
$$

which enables the Equivalent Series Resistance (ESR) calculation of capacitor and further estimates power loss. Fig. 5 shows the capacitor model with two constraints: current limit $I_{\max }^{\mathrm{RMS}}$ and hot-spot temperature limit $\left(75^{\circ} \mathrm{C}\right)$. The thermal model in it consists of the thermal resistance $R_{t h}$ and the ambient temperature, $T_{a m b}$, is assumed to be constant at $20{ }^{\circ} \mathrm{C}$. The capacitance density of this series to deduce the capacitor mass can be approximated with $1.02 \mathrm{~g} / \mu \mathrm{F}$ which is generated by linearly fitting $C_{1}$ and mass of the according capacitors. If capacitor RMS current is smaller than $I_{\max }^{\mathrm{RMS}}$, power loss can then be estimated according to RMS current and ESR. In addition, the temperature rise should be checked before outputting capacitor mass and losses.

\section{Integrated Sizing for Filter Optimization}

In [12], [14], [16], the optimization was exercised in an analytical approach after which the optimal results were validated by simulation. In contrast, this paper established the circuit simulation system in Matlab/Simulink and embedded it into the GA optimization in order to ensure the accurate optimal results.

As discussed in two sizing functions, current values in $L C$ filter should be first obtained before giving their inner resistance and judgement of constraints. But the logical paradox is 


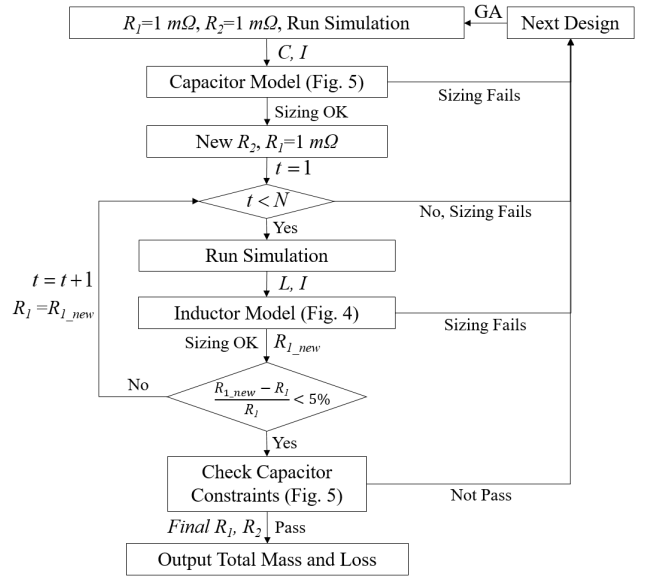

Fig. 6. Integrated sizing for filter optimization using relatively independent inductor model and capacitor model.

that the current can only be generated by simulating the system with resistance beforehand input. To this end, an integrated filter design approach is proposed to find the inner resistance after getting $L_{1}, C_{1}$ from GA, as shown in Fig. 6 .

Initially, $R_{1}$ and $R_{2}$ are both assumed as $1 \mathrm{~m} \Omega$. Then, the derived current values are applied to the capacitor model for the ESR $\left(R_{2}\right)$ calculation followed by a simulation iteration to size $L_{1}$ and deduce $R_{1}$. In this iteration, $R_{2}$ stays unchanged but inductor sizing function is exercised in a loop until the $R_{1}$ error of iteration is smaller than $5 \%$. If simulation time reaches $N$ before reaching this threshold, the filter sizing fails. After this inductor loop, capacitor model is utilized again for the final constraint check. Finally, the filter total mass and losses can be outputted.

From Fig. 6, it can be seen that the circuit system should be simulated at least twice to get one feasible design. Noting that simulation can give more precise optimal results than circuit analysis though it costs longer time. In this study, it takes around 4.4 secs to obtain one design on a standard computer, which has been considered as acceptable.

\section{FCS-MPC BASED STABILIZATION APPROACH}

FCS-MPC is utilized as the control strategy of converter regulating both DC voltage $v_{C}$ and AC filter voltage $v_{f}$. This method can provide stable control of DC link with negligible effect on the ac load regulation performance which has been proved in [19]. Before discussing GA and the optimization results, the fundamentals and applied cost function in FCSMPC are presented in this Section.

\section{A. FCS-MPC Operating Principle}

Regarding the derivation of VSC, a stationary $\alpha-\beta$ reference frame is applied for the converter modelling. Thus, all the generic three-phase voltage variable $x_{a}, x_{b}$ and $x_{c}$, are transformed into a corresponding $\alpha-\beta$ frame by applying an amplitude-invariant Clarke transformation $\mathbf{T}$ :

$$
\bar{x}=x_{\alpha}+j x_{\beta}=\mathbf{T}\left[\begin{array}{lll}
x_{a} & x_{b} & x_{c}
\end{array}\right]^{\prime}
$$

TABLE I

Voltage Vectors Used IN Two-LEVEl CONVERTER

\begin{tabular}{ccc}
\hline \hline$\left(S_{a}, S_{b}, S_{c}\right)$ & Voltage vector $\bar{v}_{i}$ & $\left(x_{a}, x_{b}, x_{c}\right)$ \\
\hline$(0,0,0)$ & $\bar{v}_{0}=0$ & $(0,0,0) v_{C}$ \\
$(1,0,0)$ & $\bar{v}_{1}=\frac{2}{3} v_{C}$ & $\left(\frac{2}{3},-\frac{1}{3},-\frac{1}{3}\right) v_{C}$ \\
$(1,1,0)$ & $\bar{v}_{2}=\frac{1}{3} v_{C}+j \frac{\sqrt{3}}{3} v_{C}$ & $\left(\frac{1}{3},-\frac{1}{3},-\frac{2}{3}\right) v_{C}$ \\
$(0,1,0)$ & $\bar{v}_{3}=-\frac{1}{3} v_{C}+j \frac{\sqrt{3}}{3} v_{C}$ & $\left(-\frac{1}{3}, \frac{2}{3},-\frac{1}{3}\right) v_{C}$ \\
$(0,1,1)$ & $\bar{v}_{4}=-\frac{2}{3} v_{C}$ & $\left(-\frac{2}{3}, \frac{1}{3}, \frac{1}{3}\right) v_{C}$ \\
$(0,0,1)$ & $\bar{v}_{5}=-\frac{1}{3} v_{C}-j \frac{\sqrt{3}}{3} v_{C}$ & $\left(-\frac{1}{3},-\frac{1}{3}, \frac{2}{3}\right) v_{C}$ \\
$(1,0,1)$ & $\bar{v}_{6}=\frac{1}{3} v_{C}-j \frac{\sqrt{3}}{3} v_{C}$ & $\left(\frac{1}{3},-\frac{2}{3}, \frac{1}{3}\right) v_{C}$ \\
$(1,1,1)$ & $\bar{v}_{7}=0$ & $(0,0,0) v_{C}$ \\
\hline \hline
\end{tabular}

where

$$
\mathbf{T}=\frac{1}{2}\left[\begin{array}{ccc}
2 & -1 & -1 \\
0 & \sqrt{3} & -\sqrt{3} \\
1 & 1 & 1
\end{array}\right]
$$

$S_{a}, S_{b}, S_{c}$ are the gate signals $(0-1)$ which determine the voltage vector of VSC. There are totally 8 voltage vectors in two-level converter and a common mode voltage drop results in the reduced voltage across the ac filter:

$$
v_{n N}=\frac{v_{a N}+v_{b N}+v_{c N}}{3} .
$$

The three-phase voltages are then given as: $v_{a n}=v_{a N}-$ $v_{n N}=S_{a} \cdot v_{C}-v_{n N}, v_{b n}=v_{b N}-v_{n N}=S_{b} \cdot v_{C}-v_{n N}$ and $v_{c n}=v_{c N}-v_{n N}=S_{c} \cdot v_{C}-v_{n N}$. Finally, the 8 possible signal combinations of the ac voltage can be obtained by using $\mathbf{T}$. These voltage vectors, represented as $\bar{v}_{i}=v_{i \alpha}+j v_{i \beta}$, are summarized in Table I together with the corresponding $\left(x_{a}\right.$, $x_{b}, x_{c}$ ). They represent 8 possible voltage vectors that are applied to the filter and linear load on ac side. The equations that describe the dynamics of ac filter are as follows:

$$
\begin{gathered}
L_{f} \frac{d \bar{i}_{f}}{d t}=\bar{v}_{i}-\bar{v}_{f}-R_{f} \bar{i}_{f} \\
C_{f} \frac{d \bar{v}_{f}}{d t}=\bar{i}_{f}-\bar{i}_{o}
\end{gathered} .
$$

Based on these two differential equations, the zero-order hold $(\mathrm{ZOH})$ discretization method is used to precisely estimate $\bar{v}_{f}$ and $\bar{i}_{f}$ since that this method can ensure the discretetime model coincides with the continuous model at sampling instants. The discretization method is given as [19]:

$$
\begin{gathered}
\bar{i}_{f}(k+1)=\bar{i}_{f}(k)+\frac{T_{s}}{L_{f}}\left(\bar{v}_{i}(k)-\bar{v}_{f}(k)-R_{f} \bar{i}_{f}(k)\right) \\
\bar{v}_{f}(k+1)=\bar{v}_{f}(k)+\frac{T_{s}}{C_{f}}\left(\bar{i}_{f}(k)-\bar{i}_{o}(k)\right)
\end{gathered}
$$

Then, the DC link dynamics is modelled by a differential equation of $v_{C}$ :

$$
C_{1} \frac{d v_{C}}{d t}=i_{d c}-i_{c}
$$

where $i_{c}$ is the current flowing into converter. It can be synthesized from the filter currents and the gating signals, as:

$$
i_{c}=S_{a} i_{f a}+S_{b} i_{f b}+S_{c} i_{f c} .
$$


After that, $v_{C}$ can be estimated by the state of charge of this capacitor during one sampling period:

$$
v_{C}(k+1)=v_{C}(k)+\left(i_{d c}-\frac{i_{c, i}+i_{c, f}}{2}\right) \cdot\left(\frac{T_{s}}{C_{1}}+R_{2}\right),
$$

where $i_{c, i}$ and $i_{c, f}$ are the initial and final currents flowing into converter during the next time step. Obviously, the former is estimated by the measured current and gating signals at $k$ instant and the latter is given by $\bar{i}_{f}(k+1)$. Both need to be computed for all possible $\bar{v}_{i} . i_{d c}$ in (15) is the DC current which should be measured at every sampling step.

\section{B. Stabilization via Cost Function}

The FCS-MPC algorithm is ended with the minimization of cost function (Fig. 7) which determines the applied voltage sector at $k+1$. The cost function consists of the errors between the predicted voltage values and their references; further, the current limiting term $G_{l i m}$ is also included:

$$
G_{\text {lim }}=\left\{\begin{array}{l}
0, \text { if }\left|\bar{i}_{f}\right| \leq i_{\max } \\
\infty, \text { if }\left|\bar{i}_{f}\right|>i_{\max }
\end{array} .\right.
$$

The control term for $v_{f}$ is given in a conventional way, as:

$$
g_{a c}=\left(v_{f \alpha}^{*}-v_{f \alpha}\right)^{2}+\left(v_{f \beta}^{*}-v_{f \beta}\right)^{2} .
$$

Both two terms are integrated into a total cost function:

$$
g_{t}=g_{a c}+\lambda_{d c} g_{C}+G_{l i m}
$$

where

$$
g_{C}=\left(v_{C}^{*}-v_{C}\right)^{2},
$$

$\lambda_{d c}$ is the WF of DC voltage control term. As this work focuses on the control preference between $v_{C}$ and $v_{f}$, other control terms (e.g. derivative of the voltage reference, switching penalization) are not considered here thus there is only one WF in $g_{t}$. In [33], two WFs are searched and optimized in a design space using neural network approach. Differently, $\lambda_{d c}$ is set as a design variable in the optimization. It is supervised by GA objectives but the design must provide good control performance. Potential filter designs can be confirmed as feasible only after they meet all the constraints in the optimization.

After using the measured signals to predict voltages on both DC and ac sides, delay compensation of $\bar{v}_{f}$ and $v_{C}$ must be utilized for the experiment concern ( [34], as shown in Fig. 7). In digital implementations, to compensate the inherent one-step computational delay, a two-step forward prediction approach is employed, which is implemented by predicting the $k+2$ instant $\bar{i}_{f}^{p}(k+2)$ and $\bar{v}_{f}^{p}(k+2)$ using the same form of (12) which stay at the same loop of $\bar{v}_{i}$ rolling optimization. Then, $v_{C}$ at $k+2$ instant can be predicted as:

$v_{C}(k+2)=v_{C}(k+1)+\left(i_{d c}-\frac{i_{c, i}^{p}+i_{c, f}^{p}}{2}\right) \cdot\left(\frac{T_{s}}{C_{1}}+R_{2}\right)$,

where $i_{c, i}^{p}$ and $i_{c, f}^{p}$ are given by $\bar{i}_{f}(k+1)$ and $\bar{i}_{f}^{p}(k+2)$ using (14). The procedure mentioned above effectively compensates

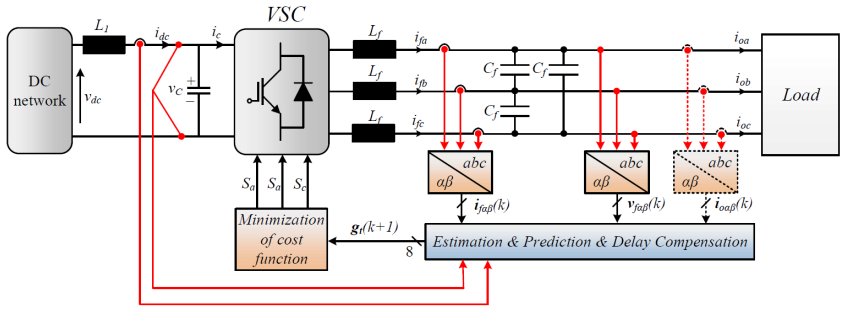

Fig. 7. Implementation of stabilization approach.

the computational delay. On the other hand, one of the basic characteristics of the FCS-MPC is that it does not comprise the PWM. In stark contrast, FCS-MPC directly governs the semiconductor switching process. Therefore, there is no delay introduced by the PWM.

\section{Optimization Procedure}

The main work is to find the optimal design of $L C$ filter. A fitness function is defined to guarantee low mass and losses of the filter. Pareto-optimal front, as will be depicted in Section VI, is given by multi-objective GA. The steps toward optimal design are based on the integrated filter sizing (Fig. 6) and GA. Thus, this section gives GA optimization process in detail.

\section{A. Optimization Variables, Constraints and Parameters}

Following the integrated sizing, $R_{1}$ and $R_{2}$ in filter are determined by multiple simulation. Therefore, they are not input variables of optimization though they vary with different designs. $L_{1}$ and $C_{1}$ are distributed by GA operators. $\lambda_{d c}$ is regarded as the third variable to find the optimal tradeoff solution between two control terms. The ranges of three variables are given in Table II together with optimization constraints and parameters. There are 6 constraints for the voltages obtained from simulation. All DC voltage constraints are from the military standard [9]. Besides, there are two constraints for $v_{f}$ : the THD limit is $3.5 \%$ and the maximum tracking error is $2.5 \mathrm{~V}$. Both are significantly sensitive to the optimization work as when they become smaller there would be lots of design points allowed to be feasible. Therefore, setting ac voltage constraints directly determines the final optimal results. The parameters of DC grid, loads and ac filter are predefined in both simulation and experiment. The turnaround time in experiment approximates $17 \mu \mathrm{s}$.

\section{B. GA Optimization Steps}

As shown in Fig. 8, the first generation of chromosomes should be created after setting GA operators. There are three operators in GA: selection, crossover and mutation [26]. As the objective is not unique, except for the population size and maximum generations, Pareto fraction should also be defined before running this algorithm.

Fig. 8 summarizes the optimization procedure. The upper rectangle part shows the running function of GA; the below rectangle depicts the main function of this study which is case-specific. In running function, a new generation of chromosomes (children) which maps variables can be created 
TABLE II

OPTIMIZATION VARIABLES, CONSTRAINTS AND PARAMETERS

\begin{tabular}{llc}
\hline \hline Variables & Filter inductance $L_{1}$ & {$[1,100] \mu \mathrm{H}$} \\
& Filter capacitance $C_{1}$ & {$[1,2000] \mu \mathrm{F}$} \\
& WF $\lambda_{d c}$ & {$[0.1,10]$} \\
Constraints & $v_{d c}$ transient & Figure 16 in [9] \\
& $v_{d c}$ distribution spectrum & Figure 18 in [9] \\
& $v_{d c}$ Max. distortion factor & 0.015 \\
& $v_{d c}$ Max. ripple & $6 \mathrm{~V}$ \\
& Max. THD of $v_{f}$ & $3.5 \%$ \\
& Max. tracking error of $v_{f}$ & $2.5 \mathrm{~V}$ \\
Paramters & DC supply $v_{s}$ & $270 \mathrm{~V}$ \\
& $v_{C}$ reference & $270 \mathrm{~V}$ \\
& AC reference voltage $v_{f}^{*}$ & $100 \mathrm{~V}$ \\
& DC grid impedance & $L_{0}=1 \mu \mathrm{H}, R_{0}=1 \mathrm{~m} \Omega$ \\
& Filter on AC side & $L_{f}=2.4 m H, C C_{f}=15 \mu \mathrm{F}$ \\
& AC linear loads & $R_{l}=60 \Omega$ \\
Sampling time of FCS-MPC & $25 \mu \mathrm{s}$ \\
Current limit term $G_{l i m}$ & $5 \mathrm{~A}$ \\
\hline \hline
\end{tabular}

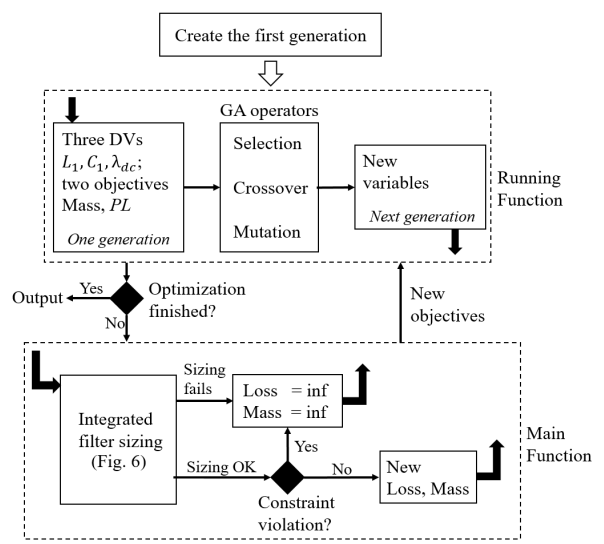

Fig. 8. Optimization procedure based on multi-objective GA.

by 3 operators after ranking the fitness of current generation (parents). If the iteration times does not exceed the preset maximum generations, individuals (only know 3 variable values) of children should go to the main function to get their objective values via the integrated sizing (Fig. 6) until reaching the maximum generation number.

The constraint violation has been discussed in the last subsection. Noting that these signal constraints do not include the components' sizing constraints (Section III). Only the design candidate that satisfies all the constraints in sizing and optimization can be considered to be feasible and then output total $P L$ and $M$. If any constraint in Table II and capacitor model (Fig. 5) is violated, objectives will be set as infinite. Moreover, in the inductor sizing (Section III.A), only if no core in the selection pool can meet all five inductor constraints, the inductor sizing fails.

\section{OptimizATION RESUlTS}

This section presents the optimization results using above sizing methods and GA optimization method which has a population size of 150 and 50 generations (lasts about 9 hours). Pareto-optimal solutions of filter mass and loss are obtained

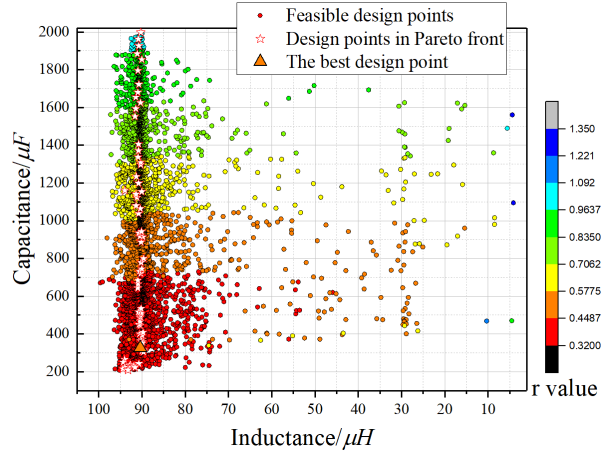

(a) Design distribution of $L_{1}, C_{1}$.

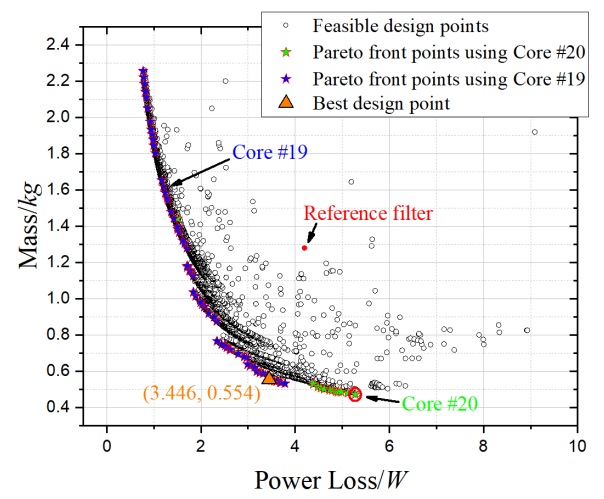

(b) Feasible design points for two objectives and the Pareto front.

Fig. 9. Feasible design results based on multi-objective GA.

and the design distribution of $L_{1}, C_{1}$ during the optimization process is depicted. Further, a study on $\lambda_{d c}$ is exercised by simulation to demonstrate its trade-off function in FCS-MPC.

\section{A. Optimal Results of Design Points}

The feasible design results using GA are presented in Fig. 9. Fig. 9(a) shows the distributions of feasible points which are marked by multi-colour circles. The colour corresponds to the value of an integrated index $(r)$ of two objectives. This index is utilized to select the best design in Pareto-front and the criterion is the minimal distance from ideal objectives [7]:

$$
\text { Solution } \equiv \min \left(r_{i}\right)
$$

where

$$
r_{i}=\sqrt{\left(\frac{M_{i}}{M_{\max }}\right)^{2}+\left(\frac{P L_{i}}{P L_{\max }}\right)^{2}},
$$

$M_{i}$ : Mass of the $i$ th solution;

$M_{\max }$ : Maximum mass;

$P L_{i}$ : Power loss of the $i$ th solution;

$P L_{\max }$ : Maximum power loss.

As seen from Fig. 9(a), there is a decreased trend of $r$ value as $L_{1}, C_{1}$ reduce. The design points in Pareto front are also shown; however, they are not all preferred solutions according to the $r$-value criterion. The best design point chosen by (21), (22) is given in Table III together with the inner resistance.

Fig. 9(b) depicts two objectives of feasible designs. In [7], equality constraints are added to the solution distribution of 
TABLE III

THREe DESIGN POINTS For EXPERIMENT

\begin{tabular}{cccc}
\hline \hline Terms of design & Best design & Core-20 design & Reference design \\
\hline$\lambda_{d c}$ & 9.32268 & 7.7298 & 0.1665 \\
$L_{1} / \mu H$ & 90.4 & 93.22 & 24.76 \\
$R_{1} / m \Omega$ & 88.94 & 97.80 & 45.84 \\
$C_{1} / \mu F$ & 326.7 & 208.87 & 1001.4 \\
$R_{2} / m \Omega$ & 11.69 & 18.29 & 6.36 \\
$P L / W\left(P_{\max }: 16.675\right)$ & 3.446 & 5.275 & 4.199 \\
$M / k g\left(M_{\max }: 2.262\right)$ & 0.5535 & 0.4714 & 1.2793 \\
$r$ value & 0.32034 & 0.3788 & 0.6192 \\
\hline \hline
\end{tabular}

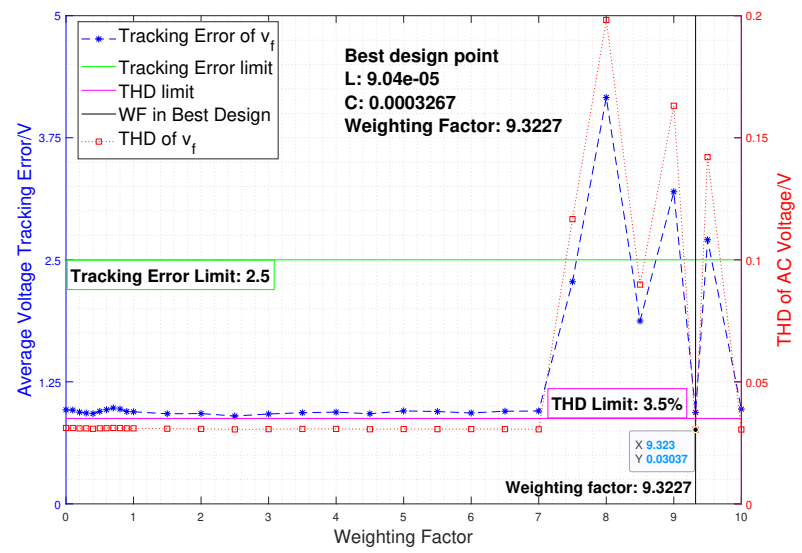

Fig. 10. Sensibility analysis of voltage control performance with regards to $\lambda_{d c}$.

Pareto front to ensure no vacancy or design gap appears in this front. In contrast, the front here is not processed by equality constraints; therefore, there are data gaps among the Paretofront points. These solutions use different cores (No. 19 and 20) for inductor sizing which also leads to their big mass differences. Another reason of data gap is from the various constraints in GA optimization which limit a lot of feasible points from Pareto-front. The best design, one Core-20 design and the reference design are marked in Fig. 9 and they are selected for the experimental validation. The design terms of Core-20 design and reference design are given in Table III.

\section{B. Study on Weighting Factor}

As discussed in Section V.A, two voltage constraints in optimization are dramatically sensitive to the optimal results. This subsection analyses the sensibility of these two limits against $\lambda_{d c}$ based on the best design point ( $L C$ values).

The best design is marked and two performance limits of $v_{f}$ are depicted in Fig. 10. Using $L_{1}$ and $C_{1}$ of the best design, give $\lambda_{d c}$ different values in the interval $(0,10]$ followed by running simulations to record the tracking error (in blue) and the THD value (in red). Both are always under their corresponding limits when $\lambda_{d c}$ is smaller than 7. However, in the other 7 samples, there are only two design points that can meet the THD limit while four designs could satisfy the tracking error limit. Thus, THD limit is relatively more sensitive to $\lambda_{d c}$ change. Noting that two samples around the

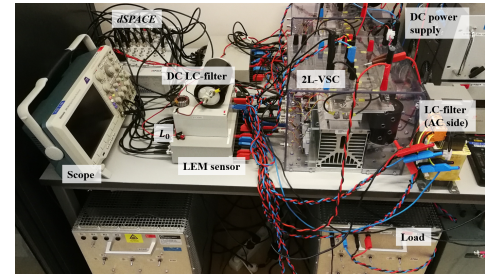

(a) Photo of experiment rig.

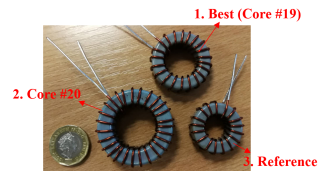

(b) Three inductors.
Fig. 11. Experimental setup for the validation.

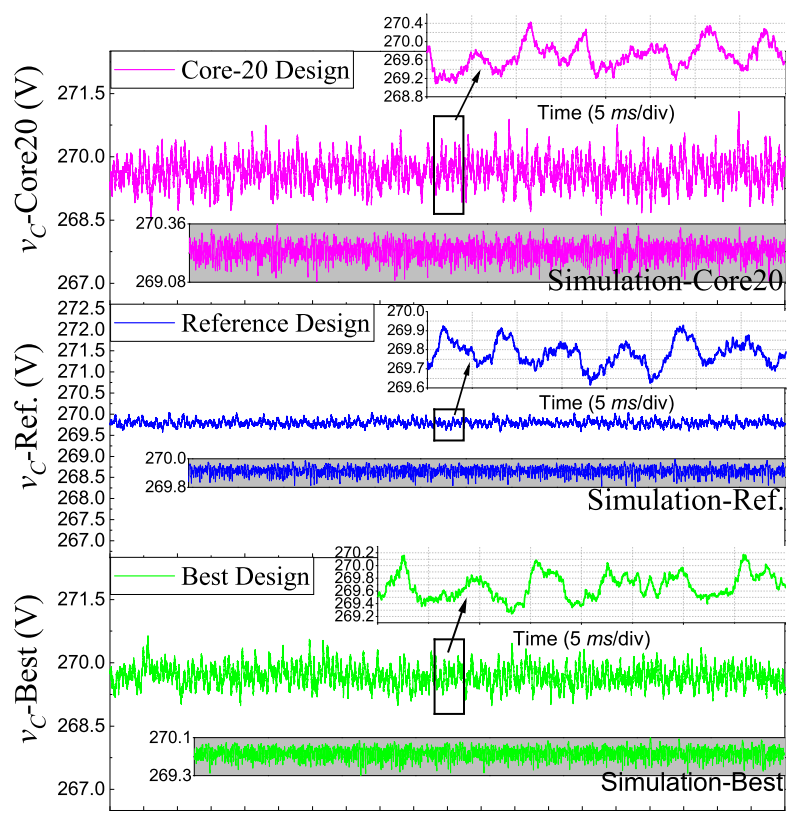

Time $(50 \mathrm{~ms} / \mathrm{div})$

Fig. 12. DC voltage results from simulation and experiment.

best design point demonstrate the excellent search ability of GA because they both violate the two limits (i.e. not feasible). Therefore, a proper $\lambda_{d c}$ for FCS-MPC can give good control performance but its value should be carefully selected.

\section{EXPERIMENT RESULTS}

Fig. 11 shows the experimental setup. The DC part consists of power supply, MG inductor $L_{0}$ and the studied $L C$ filter while the ac side is comprised of an $L C$-filtered VSC and linear loads. FCS-MPC is implemented using a dSPACE DS1202 board. Fig. 11(b) shows 3 selected inductors which are designed and manufactured following the proposed inductor sizing function (Section III.A). The 3 capacitors utilized in experiment are found to match the corresponding $C_{1}$ thus the experiment can validate the accuracy of simulation results.

$v_{C}$ results of 3 designs in both simulation (grey background) and experiment (with signals zoomed in) are depicted in Fig. 12. Results from simulations and experiments can be matched very well. Though ripple performance in experiment are not as good as simulation, all of them are acceptable. There is a clear trend that $v_{C}$ ripple declines as $C_{1}$ increases. However, the mass of capacitor will go up dramatically with the climbing $C_{1}$. Thus, the Ref. design should not be selected as a perfect 
TABLE IV

ExPerimental Performance of Three Design Points

\begin{tabular}{cccc}
\hline \hline Performance Terms & Best design & Core-20 design & Reference design \\
\hline THD & $2.36 \%$ & $3.15 \%$ & $2.7 \%$ \\
Track errors $(V)$ & 2.885 & 3.067 & 1.598 \\
Distortion factor & $8.7 \times 10^{-4}$ & $12 \times 10^{-4}$ & $2.6 \times 10^{-4}$ \\
\hline \hline
\end{tabular}

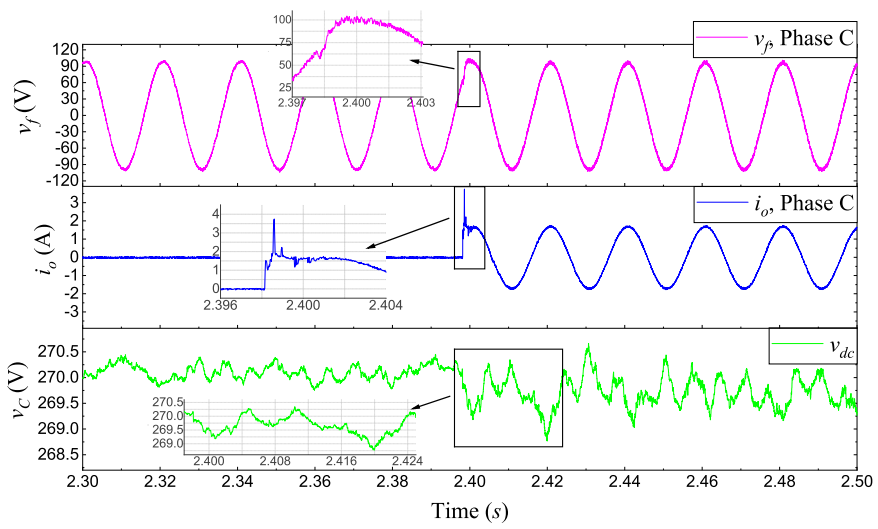

Fig. 13. Transient performance of the best design point in experiment.

$L C$ filter design though its DC stabilization is excellent. Different $L_{1}$ values can give different voltage bias but the effects are not obvious.

Fig. 13 shows the dynamic performance of the best design in experiment. As shown in the zoom-in signals, load switching has negligible effects on both AC and DC sides also $i_{o}$ can be limited by $G_{l i m}$ in (16). Table. IV summarizes the $v_{f}$ THD, tracking errors and $v_{d c}$ distortion factor performance under best design, Core- 20 and reference design. THD results are all obtained by FFT with 2-cycle signals. The tracking errors are obtained by the extracted data in Fig. 14. The best design has the best THD performance though its tracking error is a little bigger than the Reference design. Therefore, the best design provides not only the best $r$ value but excellent control performance: a similar steady-state performance with the reference design but without big $C_{1}$. That means the best design saves much also gives a good control performance based on the used FCS-MPC and GA searching ability. According to Table III, the best design saves $18 \%$ power losses and $56.7 \%$ mass comparing with the reference design. In addition, three distortion factors are all much smaller than 0.015, the maximum limit for $270 \mathrm{~V}$ DC systems [9]. The factors reflect a better DC regulation performance of the best design than the Core-20 design, which are both in the Pareto-front set of optimization.

\section{Conclusion And Future Studies}

This paper proposed an optimal filter design approach for FCS-MPC regulated converters which guarantees lower weight and power loss. Except for $L_{1}, C_{1}$ in filter, the weighting factor in the control strategy is set as a design variable in the optimization process to make sure that feasible designs can give good stabilization performance on both DC and AC voltages. After the GA-based multi-objective optimization,

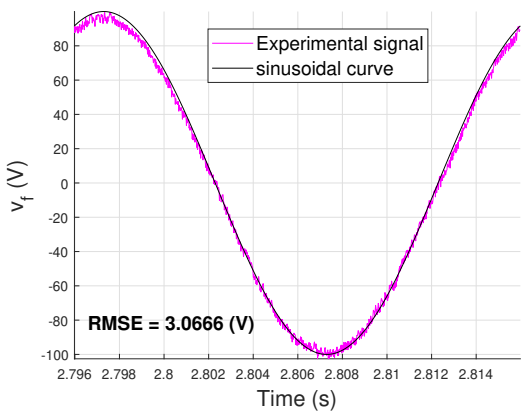

(a) Core-20 design point.

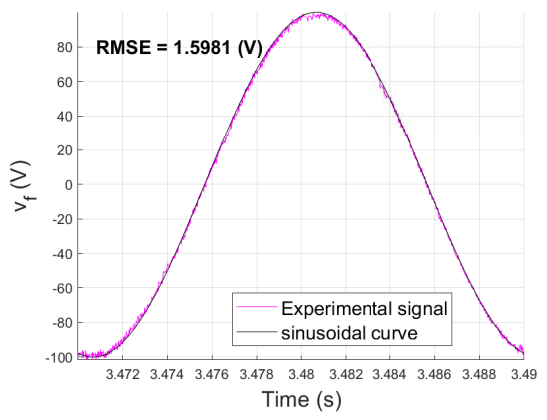

(b) Reference design point.

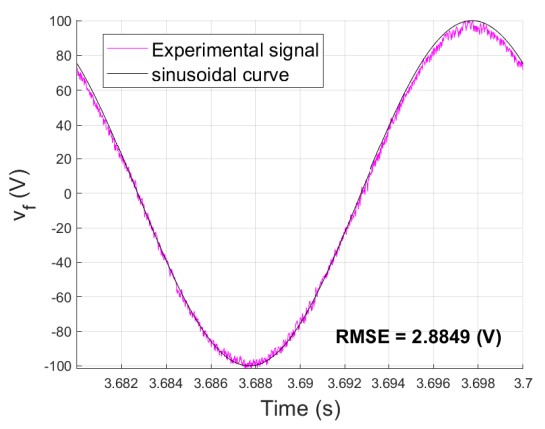

(c) Best design point.

Fig. 14. AC experimental signals under three design points.

three filter designs are selected for experiment validation. The experiment results match simulation very well and depict good control performance of used FCS-MPC. In future studies, we will consider other factors (e.g. frequency, loading profile) in the MPC controlled system to see the effects of their variations on the filter optimization. Besides, for inductor and capacitor sizing models, different weights can be added in the main function (Fig. 8) of optimization according to the practical requirements of inductor volume and capacitor reliability.

\section{ACKNOWLEDGMENT}

This project has received funding from the Clean Sky 2 Joint Undertaking under the European Union's Horizon 2020 research and innovation programme under grant agreement No 807081.

\section{REFERENCES}

[1] J. M. Carrasco, L. G. Franquelo, J. T. Bialasiewicz, E. Galvan, R. C. PortilloGuisado, M. A. M. Prats, J. I. Leon, and N. Moreno-Alfonso, 
"Power-electronic systems for the grid integration of renewable energy sources: A survey," IEEE Trans. Ind. Electron., vol. 53, no. 4, pp. 10021016,2006

[2] T. Dragičević, X. Lu, J. C. Vasquez, and J. M. Guerrero, "Dc microgrids - part i: A review of control strategies and stabilization techniques," IEEE Trans. Power Electron., vol. 31, no. 7, pp. 4876-4891, 2016.

[3] F. Gao, S. Bozhko, A. Costabeber, G. Asher, and P. Wheeler, "Control design and voltage stability analysis of a droop-controlled electrical power system for more electric aircraft," IEEE Trans. Ind. Electron., vol. 64, no. 12, pp. 9271-9281, 2017.

[4] D. Salomonsson and A. Sannino, "Low-voltage de distribution system for commercial power systems with sensitive electronic loads," IEEE Trans. Power Del, vol. 22, no. 3, pp. 1620-1627, 2007.

[5] P. Wheeler and S. Bozhko, "The more electric aircraft: Technology and challenges." IEEE Electrific. Mag., vol. 2, no. 4, pp. 6-12, 2014.

[6] J. A. Rosero, J. A. Ortega, E. Aldabas, and L. Romeral, "Moving towards a more electric aircraft," IEEE Aerosp. Electron. Syst. Mag., vol. 22, no. 3, pp. 3-9, 2007.

[7] H. Ounis, B. Sareni, X. Roboam, and A. De Andrade, "Multi-level integrated optimal design for power systems of more electric aircraft," Mathematics and Computers in Simulation, vol. 130, pp. 223-235, 2016.

[8] F. Gao, X. Zheng, S. Bozhko, C. I. Hill, and G. Asher, "Modal analysis of a pmsg-based dc electrical power system in the more electric aircraft using eigenvalues sensitivity," IEEE Trans. Transport. Electrific., vol. 1 , no. 1, pp. 65-76, 2015.

[9] Military Standard, "Aircraft electric power characteristics," Department of Defense Interface Standard (MIL-STD-704F), 2004.

[10] B. Sarlioglu and C. T. Morris, "More electric aircraft: Review, challenges, and opportunities for commercial transport aircraft," IEEE Trans. Transport. Electrific., vol. 1, no. 1, pp. 54-64, 2015.

[11] Z. Ma, X. Zhang, J. Huang, and B. Zhao, "Stability-constrainingdichotomy-solution-based model predictive control to improve the stability of power conversion system in the mea," IEEE Transactions on Industrial Electronics, vol. 66, no. 7, pp. 5696-5706, 2019.

[12] F. Wang, G. Chen, D. Boroyevich, S. Ragon, M. Arpilliere, and V. R. Stefanovic, "Analysis and design optimization of diode front-end rectifier passive components for voltage source inverters," IEEE Trans. Power Electron., vol. 23, no. 5, pp. 2278-2289, 2008.

[13] J. Muhlethaler, M. Schweizer, R. Blattmann, J. W. Kolar, and A. Ecklebe, "Optimal design of lcl harmonic filters for three-phase pfc rectifiers," IEEE Trans. Power Electron., vol. 28, no. 7, pp. 3114-3125, 2013.

[14] A. Kouchaki and M. Nymand, "Analytical design of passive lcl filter for three-phase two-level power factor correction rectifiers," IEEE Trans. Power Electron., vol. 33, no. 4, pp. 3012-3022, 2018.

[15] J. Muhlethaler, J. W. Kolar, and A. Ecklebe, "Loss modeling of inductive components employed in power electronic systems," in 8th International Conference on Power Electronics - ECCE Asia, pp. 945-952, 2011.

[16] M. Sakui and H. Fujita, "An analytical method for calculating harmonic currents of a three-phase diode-bridge rectifier with dc filter," IEEE Trans. Power Electron., vol. 9, no. 6, pp. 631-637, 1994.

[17] M. Huang, X. Wang, P. C. Loh, and F. Blaabjerg, "Llcl-filtered grid converter with improved stability and robustness," IEEE Transactions on Power Electronics, vol. 31, no. 5, pp. 3958-3967, 2016.

[18] Y. Jiao and F. C. Lee, "Lcl filter design and inductor current ripple analysis for a three-level npc grid interface converter," IEEE Transactions on Power Electronics, vol. 30, no. 9, pp. 4659-4668, 2014.

[19] T. Dragičević, "Dynamic stabilization of dc microgrids with predictive control of point-of-load converters," IEEE Trans. Power Electron., vol. 33, no. 12, pp. 10872-10884, 2018.

[20] S. Bayhan, M. Trabelsi, H. Abu-Rub, and M. Malinowski, "Finitecontrol-set model-predictive control for a quasi-z-source four-leg inverter under unbalanced load condition," IEEE Trans. Ind. Electron., vol. 64, no. 4, pp. 2560-2569, 2017.

[21] B. S. Riar, J. Scoltock, and U. K. Madawala, "Model predictive direct slope control for power converters," IEEE Trans. Power Electron., vol. 32, no. 3, pp. 2278-2289, 2017.

[22] T. Dragičević, "Model predictive control of power converters for robust and fast operation of ac microgrids," IEEE Trans. Power Electron., vol. 33, no. 7, pp. 6304-6317, 2018.

[23] S. Vazquez, J. Rodriguez, M. Rivera, L. G. Franquelo, and M. Norambuena, "Model predictive control for power converters and drives: Advances and trends," IEEE Trans. Ind. Electron., vol. 64, no. 2, pp. 935-947, 2017.

[24] S. Kouro, P. Cortes, R. Vargas, U. Ammann, and J. Rodriguez, "Model predictive control - a simple and powerful method to control power converters," IEEE Trans. Ind. Electron., vol. 56, no. 6, pp. 1826-1838, 2009.

[25] J. Rodriguez, M. P. Kazmierkowski, J. R. Espinoza, P. Zanchetta, H. Abu-Rub, H. A. Young, and C. A. Rojas, "State of the art of finite control set model predictive control in power electronics," IEEE Trans. Ind. Informat., vol. 9, no. 2, pp. 1003-1016, 2013.

[26] Kit-Sang Tang, Kim-Fung Man, Sam Kwong, and Zhi-Feng Liu, "Design and optimization of iir filter structure using hierarchical genetic algorithms," IEEE Trans. Ind. Electron., vol. 45, no. 3, pp. 481-487, 1998.

[27] A. Emadi, A. Khaligh, C. H. Rivetta, and G. A. Williamson, "Constant power loads and negative impedance instability in automotive systems: definition, modeling, stability, and control of power electronic converters and motor drives," IEEE Trans. Veh. Technol., vol. 55, no. 4, pp. 1112 $1125,2006$.

[28] A. M. Rahimi, G. A. Williamson, and A. Emadi, "Loop-cancellation technique: A novel nonlinear feedback to overcome the destabilizing effect of constant-power loads," IEEE Trans. Veh. Technol, vol. 59, no. 2, pp. 650-661, 2010.

[29] X. Zhang, D. M. Vilathgamuwa, K. Tseng, B. S. Bhangu, and C. J. Gajanayake, "Power buffer with model predictive control for stability of vehicular power systems with constant power loads," IEEE Trans. Power Electron., vol. 28, no. 12, pp. 5804-5812, 2013.

[30] F. Liu, L. Xu, Y. Li, Y. Kang, and Z. Wu, "Permanent magnet synchronous machine starter/generators based high-voltage dc parallel electric power system for the more electric aircraft," The Journal of Engineering, vol. 2018, no. 13, pp. 565-569, 2018.

[31] Magnetics, 2017 Magnetics Powder Core Catalog, ser. Toroid Data. Magnetics, May. 2017. [Online]. Available: https://www.mag-inc.com/Company/News/2017\%E5\%B9\% B411\%E6\%9C\%88/2017-Magnetics-Powder-Core-Catalog-in-Chinese

[32] Capacitor Film, Power Electronic Capacitors, Film Capacitor MKP DC B2562*, ser. MKP DC B2562*. TDK, May. 2018. [Online]. Available: https://en.tdk-electronics.tdk.com/inf/20/50/ds/B2562_.pdf

[33] T. Dragičević and M. Novak, "Weighting factor design in model predictive control of power electronic converters: An artificial neural network approach," IEEE Trans. Ind. Electron., vol. 66, no. 11, pp. 8870-8880, 2018.

[34] C. Zheng, T. Dragičević, and F. Blaabjerg, "Current-sensorless finite-set model predictive control for lc-filtered voltage source inverters," IEEE Trans. Power Electron., vol. 35, no. 1, pp. 1086-1095, 2019.

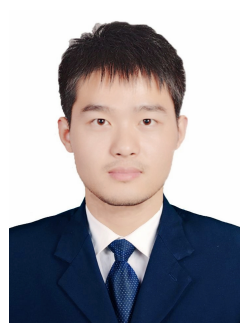

Yuan Gao (S'19) is currently pursuing the Ph.D. degree of Electrical and Electronic Engineering in the University of Nottingham, Nottingham, UK. During April-July 2019, he was a Visiting PhD Student of the Department of Energy Technology in Aalborg University, Aalborg, Denmark. He was a Postgraduate Student in the Department of Aircraft Design, Beihang University, Beijing, China from 2014 to 2017

He serves as a Reviewer in the IEEE Transactions on Industrial Electronics and IEEE Access. His research interests include filter design and optimization, model predictive control, search algorithms, machine learning applications on aircraft actuators.

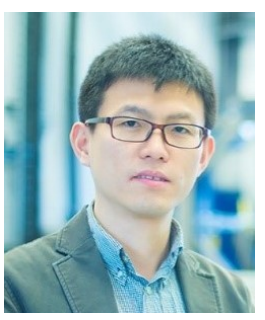

Tao Yang (M'16-SM'20) received his Ph.D. degree in electrical engineering from the University of Nottingham, Nottingham, UK, in 2013. Since then, he has been a Researcher, an Assistant Professor (2016) and is now an Associate Professor (2019) within the Power Electronics, Machines and Control Group, University of Nottingham.

His research expertise includes high-speed electric motor drive control, power electronic conversion, electrical system design and optimization for moreelectric/hybrid/all-electric aircraft applications.

Dr. Yang is an Associate Editor of IEEE Transactions on Transportation Electrification and Chinese Journal of Aeronautics. 


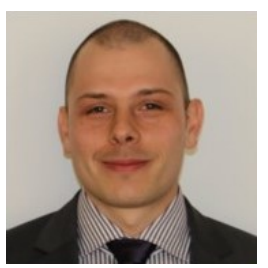

Tomislav Dragičević (S'09-M'13-SM'17) received the M.Sc. and the industrial Ph.D. degrees in Electrical Engineering from the Faculty of Electrical Engineering, University of Zagreb, Croatia, in 2009 and 2013, respectively. From 2013 until 2016 he has been a Postdoctoral researcher at Aalborg University, Denmark. From 2016 until 2020 he was an Associate Professor at Aalborg University, Denmark. From 2020 he is a Professor at the Technical University of Denmark.

He made a guest professor stay at University of Nottingham, UK during spring/summer of 2018. His research interest is application of advanced control, optimization and artificial intelligence inspired techniques to provide innovative and effective solutions to emerging challenges in design, control and cyber-security of power electronics intensive electrical distributions systems and microgrids. $\mathrm{He}$ has authored and coauthored more than 230 technical publications (more than 100 of them are published in international journals, mostly in IEEE), 8 book chapters and a book in the field.

He serves as an Associate Editor in the IEEE TRANSACTIONS ON INDUSTRIAL ELECTRONICS, in IEEE TRANSACTIONS ON POWER ELECTRONICS, in IEEE Emerging and Selected Topics in Power Electronics and in IEEE Industrial Electronics Magazine. Dr. Dragičević is a recipient of the Končar prize for the best industrial PhD thesis in Croatia, a Robert Mayer Energy Conservation award, and he is a winner of an Alexander von Humboldt fellowship for experienced researchers.

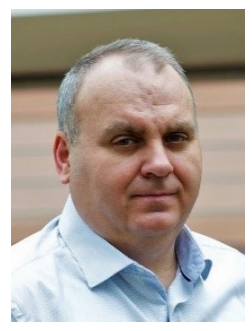

Serhiy Bozhko (M'97-SM'18) received his M.Sc and Ph.D. degrees in electromechanical systems from the National Technical University of Ukraine, Kyiv City, Ukraine, in 1987 and 1994, respectively. Since 2000, he has been with the Power Electronics, Machines and Controls Research Group of the University of Nottingham, United Kingdom, where currently he is Professor of Aircraft Electric Power Systems and Director of the Institute for Aerospace Technology. He is leading several EU- and industry funded projects in the area of aircraft electric power systems, including power generation, distribution and conversion, power quality, control and stability issues, power management and optimization, as well as advanced modelling and simulations methods.

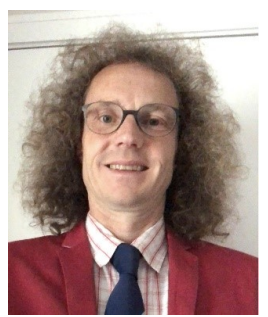

Pat Wheeler received his BEng [Hons] degree in 1990 from the University of Bristol, UK. He received his $\mathrm{PhD}$ degree in Electrical Engineering for his work on Matrix Converters from the University of Bristol, UK in 1994. In 1993 he moved to the University of Nottingham and worked as a research assistant in the Department of Electrical and Electronic Engineering. In 1996 he became a Lecturer in the Power Electronics, Machines and Control Group at the University of Nottingham, UK. Since January 2008 he has been a Full Professor in the same research group. He was Head of the Department of Electrical and Electronic Engineering at the University of Nottingham from 2015 to 2018.

$\mathrm{He}$ is currently the Head of the Power Electronics, Machines and Control Research Group, Global Director of the University of Nottingham's Institute of Aerospace Technology and is the Li Dak Sum Chair Professor in Electrical and Aerospace Engineering. He is a member of the IEEE PELs AdCom and was an IEEE PELs Distinguished Lecturer from 2013 to 2017. He has published 500 academic publications in leading international conferences and journals.

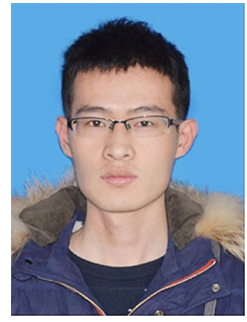

Changming Zheng (S'19) was born in Jiangsu, China. He received the B.Sc. degree in electrical engineering and automation in the College of Control Science and Engineering, China University of Petroleum (East China), Qingdao, China, in 2014, where he is currently working toward the Ph.D. degree in control theory and control engineering. From 2018 until 2020, he has been a Visiting Ph.D. Student with the Department of Energy Technology, Aalborg University, Aalborg, Denmark.

His research interests include model predictive control, application of advanced control in renewable energy systems, dc/ac microgrids, and electrical drives. 